\title{
$\alpha$-methylstyrene-assisted maleic anhydride grafted poly(lactic acid) as an effective compatibilizer affecting properties of microcrystalline cellulose/poly(lactic acid) composites
}

\author{
F. Y. Wang, L. Dai, T. T. Ge, C. B. Yue, Y. M. Song* \\ Key Laboratory of Bio-Based Material Science and Technology, Northeast Forestry University, 150040 Harbin, \\ Heilongjiang, China
}

Received 27 June 2019; accepted in revised form 18 September 2019

\begin{abstract}
A new compatibilizer, maleic anhydride-grafted poly(lactic acid) (PLA-g-AMS/MAH), was synthesized for microcrystalline cellulose (MCC)/poly(lactic acid) (PLA) composites. PLA-g-AMS/MAH copolymer was prepared by freeradical melt grafting using $\alpha$-Methylstyrene as a co-monomer and dicumyl peroxide (DCP) as a free-radical initiator. The molecular structure of the prepared PLA- $g$-AMS/MAH was characterized by Fourier transform infrared spectroscopy (FTIR), and the grafting degree $\left(D_{\mathrm{g}}\right)$ of PLA- $g$-AMS/MAH was studied by acid-alkali titration. The effects of the $D_{\mathrm{g}}$ of PLA- $g$ AMS/MAH on the rheological and mechanical properties of MCC/PLA composites were investigated. The results showed that MAH was successfully grafted onto PLA molecular chains and the $D_{\mathrm{g}}$ of PLA- $g$-AMS/MAH was dramatically higher than the $D_{\mathrm{g}}$ of PLA-g-MAH. At an AMS/MAH ratio of $2: 1$, the $D_{\mathrm{g}}$ value of the graft copolymer reached maximum. Additionally, the storage modulus, complex viscosity, equilibrium torque, and shear heat of the MCC/PLA composite melts increased with increased $D_{\mathrm{g}}$ of PLA-g-AMS/MAH. The mechanical properties of the MCC/PLA composites also were significantly improved after the addition of PLA- $g$-AMS/MAH copolymer.
\end{abstract}

Keywords: polymer composites, biopolymers, $\alpha$-methylstyrene, grafting degree, interface

\section{Introduction}

With decreasing petroleum resources and increasing solid plastic waste, there is an increased need for the development of environmentally-friendly, biodegradable materials [1-3]. Biodegradable polymers have received extensive attention, with extensive study of aliphatic polyesters, such as polylactic acid (PLA), grafting poly(3-hydroxybutyrate-co-3-hydroxyvalerate), and poly- $\beta$-hydroxybutyrate (PHB) [4-6]. PLA is a fully biodegradable thermoplastic polymer that is produced by the fermentation of maize, wheat, straw, or other plant resources followed by posterior ringopening polymerization $[7,8]$. PLA offers several advantages, such as high strength, high stiffness, and biocompatibility, allowing its widespread use in textiles, packaging, and medical and automotive fields [9-13]. However, PLA has several drawbacks that limit its application, including high brittleness, relatively high price, and processing instability [14].

As a strategy to improve the defects of PLA and decrease costs, these materials have been mixed with low-cost natural fibers and other natural materials, such as microcrystalline cellulose (MCC) $[15,16]$, starch [17], protein [18], and cellulose nanospheres [19]. MCC is easily obtained from lignocellulose and is the product of natural cellulose hydrolyzed by dilute 
acid to its leveling-off degree of polymerization (LODP), with a particle size of about 20 to $80 \mu \mathrm{m}$ $[15,16,20]$. MCC has advantages of small size, good fluidity, high modulus, high strength, and good degradability, allowing its potential use in composite reinforcement $[21,22]$ to reduce total costs and enhance the mechanical properties of the materials.

The surface of MCC contains hydroxyl groups $(-\mathrm{OH})$, resulting in superior wettability and higher reactivity of this material. However, due to the hydrophilicity of MCC and the hydrophobicity of PLA, when MCC is combined with PLA, the difference between these two materials may result in poor interface adhesion and agglomeration of MCC particles $[23,24]$. Therefore, the improvement of the interfacial compatibility between the reinforcing material and the matrix is essential to enhance the properties of MCC/PLA composites. Many methods have been used for the modification of PLA, including silane modification [25], mercerization [26], alkali treatment [27], and acetylation [28]. Nevertheless, the addition of compatibilizers has significant effects on the interfacial compatibility of composites [29]. Some researchers demonstrated that polyethylene glycol compatibilizer significantly improved mechanical properties of CNC/PLA composites and dispersion of cellulose nanocrystals (CNC) in PLA matrix [30].

A polar unit can be grafted on the resin macromolecular chain by melt graft copolymerization to obtain a compatibilizer which can effectively improve the interfacial compatibility of PLA composites. Maleic anhydride (MAH)-grafted PLA is a good compatibilizer in PLA blends with starch, clay, and natural fiber [31-33]. The $D_{\mathrm{g}}$ and molecular weight of MAHgrafted PLA determine the compatibilizing effect of these materials [34]. However, the $D_{\mathrm{g}}$ of MA-grafted PLA is usually low because MA has low reactivity toward PLA macroradicals [35]. Therefore, in order to obtain higher $D_{\mathrm{g}}$, the reactivity of PLA molecules with MA monomers must be increased. The addition of co-monomers, such as styrene (St), AMS, and divinylbezene (DVB), can increase the activity of MAH and enhance the $D_{\mathrm{g}}$ and also inhibit the degradation of the polymer [36, 37].

AMS is a good electro-donating monomer, and can interact with MAH through charge transfer complexes or can copolymerize with MAH under certain conditions [37]. In this study, to solve the problem of poor compatibility between MCC and PLA, we synthesized a new copolymer, AMS-assisted MAH grafted onto PLA (PLA- $g$-AMS/MAH), as a compatibilizer of the MCC/PLA system. The effects of PLA$g$-AMS/MAH with different $D_{\mathrm{g}}$ values on the mechanical properties, morphology, and the rheological properties of prepared MCC/PLA composites were comprehensively studied. The results of this work will assist future efforts to improve the selection of a compatibilizer for specific applications of composite materials and optimize compatibilizer function for composite materials processing.

\section{Materials and methods}

\subsection{Materials}

PLA 3001D from Nature Works (USA) was used $\left(\rho=1.24 \mathrm{~g} / \mathrm{cm}^{3}, \quad M_{\mathrm{w}}=72000 \mathrm{~g} / \mathrm{mol}, \quad\right.$ MFR $=$ $13.6 \mathrm{~g} / 10 \mathrm{~min}, 5 \$ / \mathrm{kg}$ ). MCC (SH-105, with 30 $50 \mu \mathrm{m}$ particle size, $2 \$ / \mathrm{kg}$ ) was supplied by Anhui Sunhere Pharmaceutical Excipients Co. Ltd., China. $\mathrm{MAH}$, acetone, tetrahydrofuran, chloroform, and ethanol were purchased from Tianjin Guangfu Fine Chemical Co. Ltd, China. AMS and DCP of analytical grade were procured from Shanghai Aladdin Biochemical Technology Co. Ltd. and Shanghai Macklin Biochemical Co., Ltd., respectively.

\subsection{Preparation of samples}

\subsubsection{PLA-g-AMS/MAH}

MAH, AMS, and DCP were dissolved at different proportions in an appropriate amount of acetone (see Table 1) and then sprayed onto the surface of PLA pellets to obtain a uniform distribution of chemicals in the mixtures. The mixtures were then melt-blended to obtain PLA-g-AMS/MAH using a torque rheometer (HAAKE PolyLab OS, Thermo Electron, Karlsruhe, Germany) at $180^{\circ} \mathrm{C}$ and a fixed speed of $50 \mathrm{r} / \mathrm{min}$ for $8 \mathrm{~min}$. After cooling, granulation, and drying, the graft copolymers were ready for use. For

Table 1. Composition of PLA- $g$-AMS/MAH samples.

\begin{tabular}{|c|c|c|c|c|c|}
\hline \multirow{2}{*}{$\begin{array}{c}\text { Samples } \\
\text { code }\end{array}$} & \multicolumn{4}{|c|}{ Formulation } & \multirow{2}{*}{$\begin{array}{c}\text { Grafting } \\
\text { temperature } \\
{\left[{ }^{\circ} \mathrm{C}\right]}\end{array}$} \\
\hline & PLA & МАН & AMS & DCP & \\
\hline $\mathrm{P}$ & 100 & 0 & 0 & 0 & 180 \\
\hline PA0 & 100 & 4.5 & 0 & 0.45 & 180 \\
\hline PA1 & 100 & 4.5 & 2.25 & 0.45 & 180 \\
\hline PA2 & 100 & 4.5 & 4.50 & 0.45 & 180 \\
\hline PA4 & 100 & 4.5 & 9.00 & 0.45 & 180 \\
\hline PA8 & 100 & 4.5 & 18.00 & 0.45 & 180 \\
\hline
\end{tabular}

Note: formulations presented in Table 1 are expressed as weight parts. 
comparison, un-modified PLA and PLA- $g$-MAH were processed under the same conditions.

\subsubsection{Preparation of MCC/PLA composites}

MCC was dried for $12 \mathrm{~h}$ at $103^{\circ} \mathrm{C}$, and PLA was dried for $12 \mathrm{~h}$ at $50^{\circ} \mathrm{C}$ in a vacuum oven before composite fabrication. The MCC, PLA- $g-\mathrm{AMS} / \mathrm{MAH}$, and PLA resin were premixed in a high-speed blender (SHR-10A, Tonghe Zhangjiagang Machinery, Zhangjiagang, China) at room temperature for $10 \mathrm{~min}$. Then, the mixtures were transferred to a twin-screw extruder $(L / D=36$, throughput of $4 \mathrm{~kg} / \mathrm{h}$, SJSH-30, Nanjing Jiangsu Machinery, Nanjing, China). The temperature of the extruder barrel was set at $155 / 160 / 170 / 180 / 180 / 170 / 165^{\circ} \mathrm{C}$ (from the feeder zone to the die), and the rotation speed was set to $30 \mathrm{rpm}$. Extrudate pellets were molded into composite sheets in a plastic compression molding press (SL-6, Harbin Special Plastic Products, Harbin, China) at $180^{\circ} \mathrm{C}$ at a constant pressure of $10 \mathrm{MPa}$. The pressed MCC/PLA composite samples were then cut into standard specimens by bench saw (XJ-300, Harbin Special Plastic Products, Harbin, China) for subsequent testing. The compositions of the various MCC/PLA composites were determined and are presented in Table 2.

\subsection{Characterization}

\subsubsection{Fourier transform infrared (FTIR) spectroscopy}

In the experiment, approximately $3 \mathrm{~g}$ of the processed PLA-g-AMS/MAH sample was dissolved in $150 \mathrm{~mL}$ chloroform using reflux, followed by precipitation in excessive ethanol after cooling. The precipitates were filtered out and then washed three times with fresh ethanol to remove unreacted monomers, and then dried in a vacuum oven at $50^{\circ} \mathrm{C}$ for $12 \mathrm{~h}$. The

Table 2. Composition of various MCC/PLA composites.

\begin{tabular}{|c|c|c|c|c|}
\hline \multirow[b]{2}{*}{ Sample } & \multirow{2}{*}{$\begin{array}{c}\text { PLA } \\
{[\% \text { mass }]}\end{array}$} & \multirow{2}{*}{$\begin{array}{c}\text { MCC } \\
{[\% \text { mass] }}\end{array}$} & \multicolumn{2}{|c|}{ PLA-g-AMS/MAH } \\
\hline & & & $\begin{array}{c}\text { Sample } \\
\text { code }\end{array}$ & $\begin{array}{l}\text { Mass } \\
{[\%]}\end{array}$ \\
\hline PC & 80 & 20 & $\mathrm{P}$ & 3 \\
\hline PCA0 & 80 & 20 & PA0 & 3 \\
\hline PCA1 & 80 & 20 & PA1 & 3 \\
\hline PCA2 & 80 & 20 & PA2 & 3 \\
\hline PCA4 & 80 & 20 & PA4 & 3 \\
\hline PCA8 & 80 & 20 & PA8 & 3 \\
\hline
\end{tabular}

Notes: Formulations are expressed as weight parts. Addition of PLA-g-AMS/MAH equal to $3 \%$ of the weight of the MCC and PLA. graft copolymers were then characterized using an FTIR spectrometer (Thermo Nicolet 6700, Thermofisher, Waltham, MAH, USA). The FTIR spectra were recorded in the range of $600 \sim 4000 \mathrm{~cm}^{-1}$. The attenuated total reflection (ATR)-FTIR method was used for the FTIR characterization.

\subsubsection{Acid-alkali titration}

The $D_{\mathrm{g}}$ of purified PLA- $g$-AMS/MAH was measured by acid-alkali titration. First, the purified sample with a mass of $W[\mathrm{~g}]$ was dissolved in tetrahydrofuran, and then $0.05 \mathrm{~mol} / \mathrm{L} \mathrm{NaOH}$-ethanol standardized solution was added, and the mixture was reflux heated for $0.5 \mathrm{~h}$ at $65^{\circ} \mathrm{C}$. The appropriate end of titration was judged by using thymol blue as an indicator. The prepared solution was titrated with $0.05 \mathrm{~mol} / \mathrm{L}$ $\mathrm{HCl}$-ethanol standardized solution while still hot, and the consumed $\mathrm{HCl}$ volume $V[\mathrm{~mL}]$ was recorded. The grafting degree $\left(D_{\mathrm{g}}\right)$ of the MAH was obtained via Equation (1):

$D_{\mathrm{g}}=\frac{98.06 C\left(V_{0}-V_{1}\right)}{2 \cdot 1000 \mathrm{~W}}$

where $C$ is the $\mathrm{HCl}$ concentration of $0.05 \mathrm{~mol} / \mathrm{L}, V_{0}$ is the volume of $\mathrm{HCl}$ consumed by the neat PLA [mL], $V$ is the volume of $\mathrm{HCl}$ consumed by the PLA- $g$ AMS/MAH [mL], and $W$ is the weight of each sample $[\mathrm{g}]$.

\subsubsection{Melt flow rate}

Melt flow rate (MFR) measurements were performed on a tester (ZRZ1452, MTS Systems Co, LTD) at $190^{\circ} \mathrm{C}$ with a load of $2.16 \mathrm{~kg}$, according to the ASTMD1238 standard. The MFR of the sample was obtained via Equation (2):

$\mathrm{MFI}=\frac{600 M}{t}$

where $M$ is the extrudate weight in grams, and $t$ is the test time in seconds

\subsubsection{Rotational rheometry}

A rotational rheometer (AR2000ex, TA Instruments, New Castle, DE, USA) was used to evaluate the dynamic rheological properties of the MCC/PLA composites. Diameter of $25 \mathrm{~mm}$ and ETC parallel plate geometry were selected for the test, with the following parameters: gap $=2000 \mu \mathrm{m}$, temperature $=$ $180^{\circ} \mathrm{C}$, strain $=0.1 \%$ (within the linear viscoelastic region), and frequency range of $628.3 \sim 0.06283 \mathrm{rad} / \mathrm{s}$. 
Three replicates were performed for each formulation.

\subsubsection{Torque rheometry}

Extruded MCC/PLA pellets were tested using a torque rheometer (HAAKE PolyLab OS, Thermo Electron, Karlsruhe, Germany) with roller rotors. The testing temperature was $180^{\circ} \mathrm{C}$, and the rotor speed was $50 \mathrm{r} / \mathrm{min}$ for $10 \mathrm{~min}$ with a constant filling degree of $75 \%$. The average values of the torque and temperature during the last $2 \mathrm{~min}$ of the test were considered the equilibrium torque and temperature values of the sample.

\subsubsection{Mechanical property tests}

The tensile and flexural properties of the composites were evaluated following ASTM D638-2014 and ASTM D790-2010, respectively, on an electronic universal mechanical testing machine (CMT5504; MTS Systems, Shenzhen, China) at a crosshead speed of $5 \mathrm{~mm} / \mathrm{min}$. The Charpy impact property of the composites was tested using an impact-testing machine (XJ-50G, Chengde Dahua Testing Machine, Chengde, China) according to GB/T 1043.1-2008. The measurements were performed under ambient conditions and relative humidity of approximately $50 \%$. Eight replicate specimens of each sample were tested.

\subsubsection{Scanning electron microscopy (SEM)}

The fracture surface of the MCC/PLA composites were sputter-coated with gold and then observed using a scanning electron microscope (Quanta 200, FEI, Hillsboro, OR, USA) at an acceleration voltage of $15 \mathrm{kV}$.

\section{Results and discussion}

\subsection{FTIR analysis}

The FTIR spectra of pure PLA, PLA-g-MAH, and PLA-g-MAH/AMS samples were determined and are shown in Figure 1. There was a sharp absorption peak at $1750 \mathrm{~cm}^{-1}$, which was related to the asymmetric stretching vibration of the carbonyl $(\mathrm{C}=\mathrm{O})$ [38]. Compared with the FTIR data for the neat PLA, the $\mathrm{C}=\mathrm{O}$ peak intensity of grafted copolymers was obviously enhanced because of the superposition of $\mathrm{C}=\mathrm{O}$ present in PLA and MAH [38]. Another $\mathrm{C}=\mathrm{O}$ absorption peak of MAH was observed at $1860 \mathrm{~cm}^{-1}$, which was due to the vibrational coupling of the carbonyl functional group in $\mathrm{MAH}$, indicating the successful

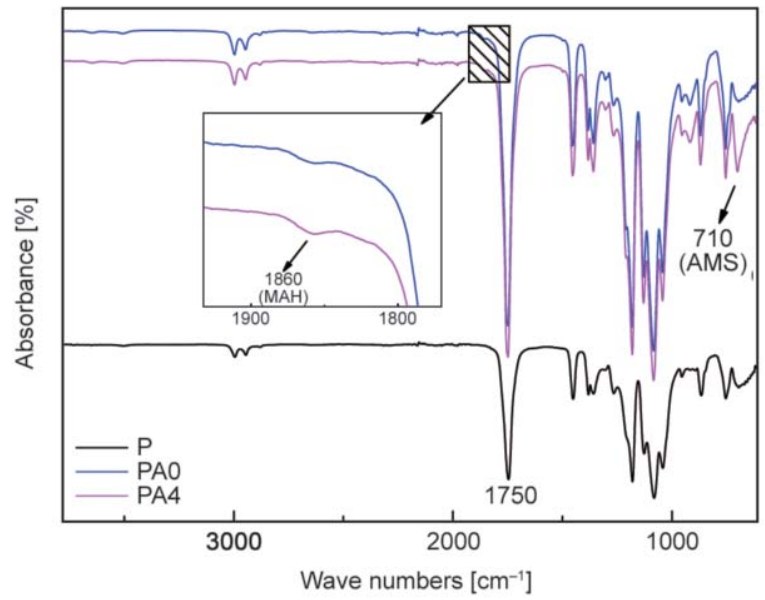

Figure 1. FTIR spectra of pure PLA, PLA- $g-\mathrm{MAH}$, and PLA-g-MAH/AMS.

grafting of MAH onto PLA [39]. It can be clearly seen from the data presented in Figure 1 that with addition of AMS, the absorption peak area of the $\mathrm{C}=\mathrm{O}$ at $1860 \mathrm{~cm}^{-1}$ was slightly increased, indicating increased grafting of MAH onto the PLA chains.

A new absorption peak appeared at $710 \mathrm{~cm}^{-1}$, which belonged to the asymmetric stretching vibration of the AMS characteristic phenyl group [40, 41]. Importantly, the peak at $1630 \mathrm{~cm}^{-1}$ of carbon-carbon double bond $(\mathrm{C}=\mathrm{C})$ stretching vibration was not observed, which confirmed the absence of unreacted MAH and AMS monomers in the purified samples. In conclusion, these results indicated the successful grafting of $\mathrm{co}$-monomer AMS on PLA molecular chains to form the PLA-g-AMS/MAH copolymer.

\section{2. $D_{\mathrm{g}}$ analysis}

As shown in Figure 2, the addition of AMS comonomer markedly increased the $D_{\mathrm{g}}$ of the MAH, and the $D_{\mathrm{g}}$ gradually increased with the increase of

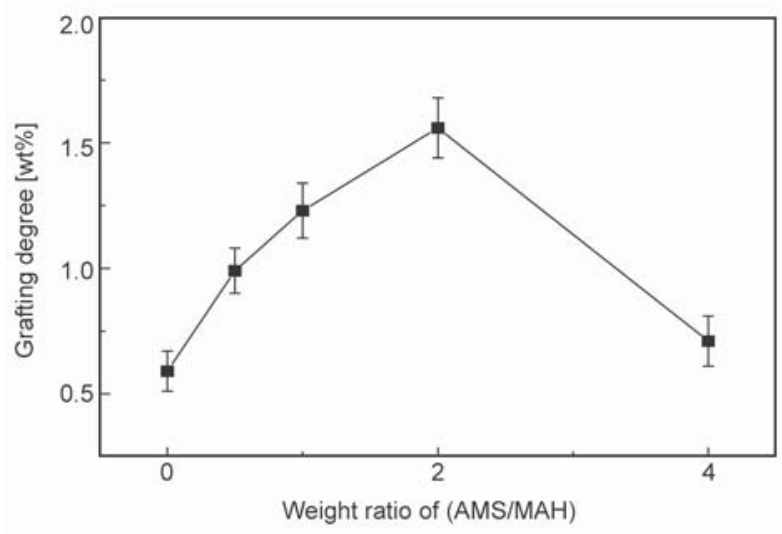

Figure 2. The effects of different AMS/MAH weight ratios on the grafting degree $\left(D_{\mathrm{g}}\right)$ of the MAH. 


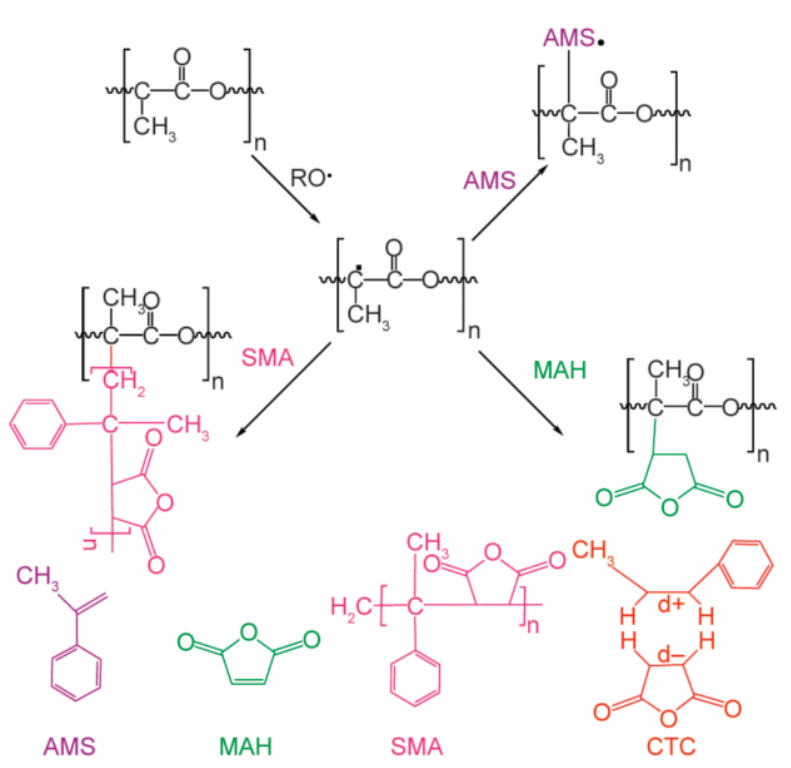

Figure 3. Possible mechanism for melt grafting of MAH onto PLA with AMS as the co-monomer.

AMS/MAH weight ratio. When the weight ratio was $2: 1$, the $D_{\mathrm{g}}$ of MAH reached the maximum value of $1.56 \mathrm{wt} \%$, an approximate $264 \%$ increase compared to the material lacking AMS. However, the $D_{\mathrm{g}}$ of MAH decreased dramatically with further ratio increase, indicating that there is an optimal ratio between MAH and AMS. In this experiment, this ratio of AMS/MAH was 2:1, and this result may be related to the grafting mechanism. The possible mechanism of the grafting reaction is shown in Figure 3.

Due to structural symmetry and low electron density around the $-\mathrm{CH}=\mathrm{CH}-$ bond, $\mathrm{MAH}$ has low reactivity toward macroradicals, resulting in low $D_{\mathrm{g}}$ of MAH on the PLA chain. AMS is an electron-donating monomer and can interact with MAH to form a chargetransfer complex (CTC) that enhances the electric asymmetry on the $-\mathrm{CH}=\mathrm{CH}$ - bond of $\mathrm{MAH}$, causing high reactivity $[36,41]$. In the case of $\mathrm{m}(\mathrm{AMS})$ : $\mathrm{m}(\mathrm{MAH})<2: 1$, with increased AMS content, more CTC may be formed and AMS can form AMS-co$\mathrm{MAH} \bullet(\mathrm{SMA})$ that can react with macroradicals (PLA $\bullet$ ), leading to a notable increase in $D_{\mathrm{g}}$. MAH is then grafted onto the PLA main chain by MAH monomer(MA $\bullet$ ) and SMA. For m(AMS):m(MAH) $>2: 1$, the presence of additional AMS would produce SMA that would be terminated with free radicals such as AMS•, MAH• dition of excess AMS would consume PLA macroradicals and generate AMS macroradicals (PLA-gAMS•) with lower reactivity toward SMA macroradicals than that of PLA $\bullet$, resulting in the grafting of fewer MAH monomers onto the PLA backbone for decreased $D_{\mathrm{g}}$ of MAH $[36,37,40]$.

\subsection{MFR analysis}

The influence of various AMS/MAH ratios on the MFR of the different copolymers was determined and is displayed in Table 3. The MFR reflects the melt flow characteristics and molecular weight of materials. The occurrence of free-radical melt grafting led to the reduction of MFR values of the PLA copolymers. Additionally, the presence of AMS also caused a decrease of MFR. Consistent with the $D_{\mathrm{g}}$ results, the lowest MFR value was $11.4 \mathrm{~g} / 10 \mathrm{~min}$, which occurred at the weight ratio of $2: 1$. This suggested an increase of the PLA molecular weight and decrease of the PLA melt flowability. Because the addition of AMS can form SMA and then graft onto the PLA chain, the greater the addition of AMS into the grafting system correlated with the formation of more branched chains and decreased MFR of the grafted samples. Nevertheless, the MFR did not decrease consistently, because excessive AMS results in the preferential grafting of AMS onto the PLA backbone, hindering the grafting of SMA and reducing the molecular weight of the copolymer, resulting in a higher MFR value [37].

\subsection{Dynamic rheological properties}

The changes of storage modulus $\left(G^{\prime}\right)$ and complex viscosity $\left(\eta^{*}\right)$ versus frequency were next investigated, as shown in Figure 4. Figure 4a shows that the $G^{\prime}$ of MCC/PLA composites increased with increasing frequency. The introduction of graft copolymers as compatibilizers, the $G^{\prime}$ of MCC/PLA composites increased significantly, reflecting improved melt elasticity, which means improvement of rigid and processing rheological property of MCC/PLA composites.

Table 3. Melt flow rate of PLA and grafted copolymer.

\begin{tabular}{|c|c|}
\hline Sample & $\begin{array}{c}\text { MFR } \\
{[\mathbf{g} /(\mathbf{1 0} \text { } \mathbf{m})]}\end{array}$ \\
\hline P & $20.14 \pm 1.10$ \\
\hline PA0 & $19.33 \pm 0.99$ \\
\hline PA1 & $16.66 \pm 0.59$ \\
\hline PA2 & $15.34 \pm 0.92$ \\
\hline PA4 & $11.40 \pm 1.32$ \\
\hline PA8 & $17.50 \pm 1.03$ \\
\hline
\end{tabular}

Note: P reflect PLA which process by torque rheometer. The MFR of orginal PLA is $13.6 \mathrm{~g} / 10 \mathrm{~min}$. 

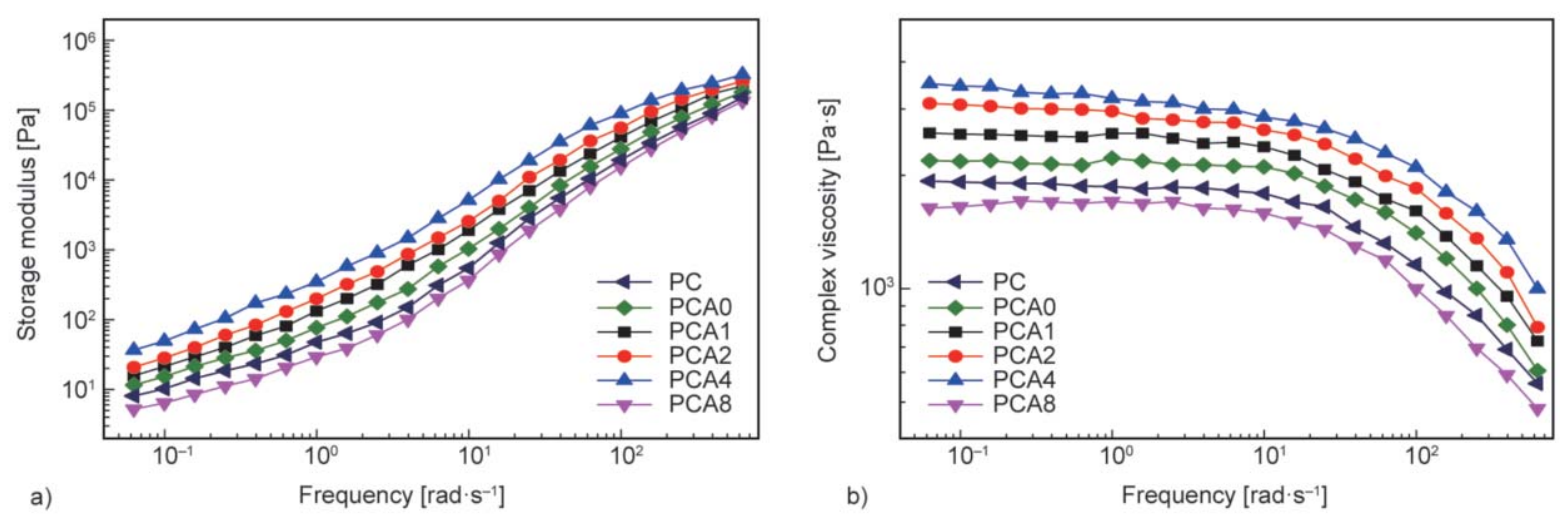

Figure 4. Dynamic rheological properties of MCC/PLA composites with different PLA-g-AMS/MAH: (a) storage modulus versus frequency and (b) complex viscosity versus frequency.

A comparison of the effects of PLA- $g$-AMS/MAH with different $D_{\mathrm{g}}$ on the composites revealed that the higher the $D_{\mathrm{g}}$ of the compatibilizer, the greater the $G^{\prime}$ values of the composites. Therefore, the PCA4 samples, containing PA4 with $D_{\mathrm{g}}=1.56 \mathrm{wt} \%$, exhibited the highest $G^{\prime}$ value, indicating enhanced interaction and improved compatibility between MCC and PLA. As shown in Figure $4 b$, the $\eta^{*}$ of the MCC/PLA composite melt presented a decreasing trend with increasing frequency, consistent with the shear-thinning behavior of pseudoplastic fluid. With the addition of compatibilizer, the $\eta *$ of MCC/PLA composite melt increased. This may be due to reaction between the anhydride on the surface of PLA- $g$-AMS/ MAH and the hydroxyl groups $(-\mathrm{OH})$ on the surface of the MCC to form ester bonds. Hydrogen bonds were also formed between molecules. Under the action of these two binding forces, the interfacial adhesion between the MCC and PLA further improved, resulting in a decrease of melt flowability and an increase of melt strength. Furthermore, the $\eta^{*}$ increased with the increase of $D_{\mathrm{g}}$ of PLA-g-AMS/ $\mathrm{MAH}$, and the PCA4 samples had maximum value. The $D_{\mathrm{g}}$ value correlates with the quantity of the anhydride that reacted with the $-\mathrm{OH}$ in the copolymer, which means that more reactions may occur at higher $D_{\mathrm{g}}$ value, leading to an increase of the intermolecular force and increasing the $\eta^{*}$ of the MCC/PLA composites.

Both $G^{\prime}$ and $\eta^{*}$ values in the PCA8 sample dramatically decreased, even below those of the neat samples, as shown in Figure 4. Little anhydride of PA8 reacted with MCC because the $D_{\mathrm{g}}$ was only $0.61 \mathrm{wt} \%$ (Figure 2). However, the MFR of PA8 was higher than the MFR of PLA (Table 3), indicating that the molecular weight of PA8 was lower than that of PLA and allowing PLA-g-AMS/MAH to contribute to lubrication and plasticization [42]. The $\eta^{*}$ and $G^{\prime}$ of the MCC/PLA composites reduced under the synergistic effect of these factors, though the presence of compatibilizer had a positive effect on the MCC/PLA composites.

\subsection{Torque rheometry}

The temperature and torque of MCC/PLA composite systems with different compatibilizers were determined, as shown in Figure 5 and in Table 4. The equilibrium torque $\left(T_{\mathrm{e}}\right)$ reflects the apparent viscosity and flow properties of the materials, and the $\Delta T$ is defined as the difference between the equilibrium temperature and the initial temperature and represents the shearing heat.

It can be seen from Figure 5 that the torque of the composite system rapidly increased and peaked in the initial stage of the test because the solid pellets fed into the mixing chamber, which hindered the movement of the rotors. Subsequently, under the influence

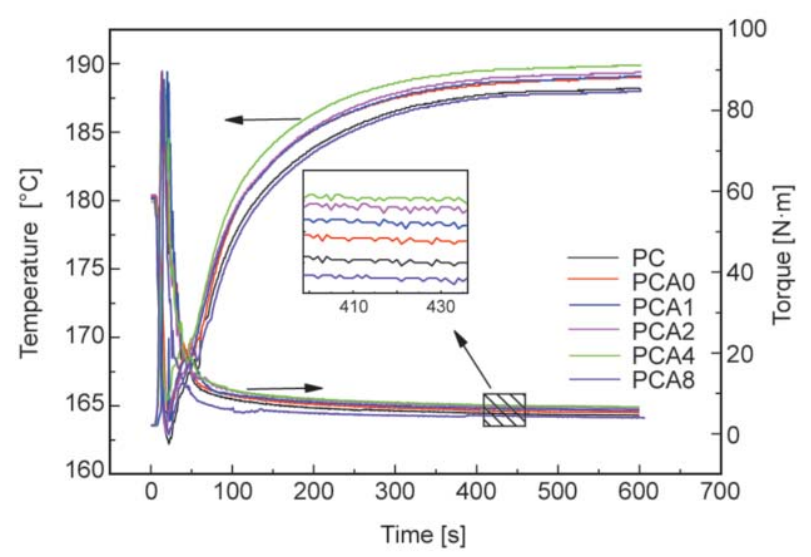

Figure 5. Curves of torque and temperature versus time of MCC/PLA composites prepared with different PLA- $g$-AMS/MAH. 
Table 4. Torque rheological parameters of the MCC/PLA composites prepared with different Amounts of PLA- $g$-AMS/MAH.

\begin{tabular}{|c|c|c|}
\hline Sample & $\begin{array}{c}\boldsymbol{T}_{\mathbf{e}} \\
{[\mathbf{N} \cdot \mathbf{m}]}\end{array}$ & $\begin{array}{c}\Delta \boldsymbol{T} \\
{\left[{ }^{\circ} \mathbf{C}\right]}\end{array}$ \\
\hline PC & 4.66 & 8.17 \\
\hline PA0 & 5.36 & 8.58 \\
\hline PA1 & 5.88 & 8.76 \\
\hline PA2 & 6.35 & 8.85 \\
\hline PA4 & 6.81 & 9.89 \\
\hline PA8 & 4.13 & 7.77 \\
\hline
\end{tabular}

of heating and shearing, the MCC/PLA composites gradually melted and the torque reduced correspondingly. When the composite systems were completely melted and evenly blended, equilibrium was achieved [43]. Combined with the data presented in Table 4, the addition of compatibilizer increased the $T_{\mathrm{e}}$ value of the MCC/PLA composite system. The highest value of $T_{\mathrm{e}}$ was obtained for the PCA4 samples, which corresponds to the highest apparent viscosity. This confirmed the calculated $\eta^{*}$ values (Figure 4), indicating that PLA-g-AMS/MAH with higher $D_{\mathrm{g}}$ indeed improved the compatibility between MCC and the PLA matrix.

Figure 4 also illustrates the change of temperature with the extrusion of solid pellets to the mixing chamber. There was an initial reduction of the melt temperature, and then a rapid increase due to the heat produced by shear friction, until finally reaching equilibrium. A comparison of the $\Delta T$ of different MCC/ PLA composites shows that the $\Delta T$ of the samples steadily increased with increasing $D_{\mathrm{g}}$ of the compatibilizer, with the maximum obtained in the PCA4 samples. This finding further showed that there was a positive correlation between compatibilization effect and the $D_{\mathrm{g}}$ of the compatibilizer.

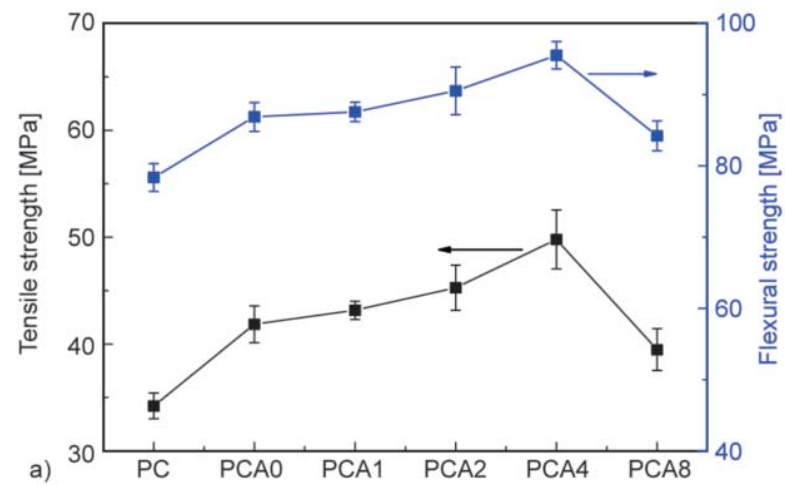

\subsection{Mechanical properties}

The mechanical properties were determined and are shown in Figure 6. The MCC/PLA composites in the presence of different compatibilizers exhibited higher strength than the PC control samples. The compatibilizer improved the mechanical properties of $\mathrm{MCC} /$ PLA composites by enhancing the interfacial bonding strength between MCC and PLA. The compatibilizer showed good compatibility with the PLA matrix and was able to react with MCC particles, which lowered the surface polarity of MCC and reinforced the dispersion and wettability of MCC in the PLA matrix. The possible compatibilization mechanism is shown in Figure 7. The anhydride groups of the compatibilizer have high polarity and reactivity, allowing reaction with the $-\mathrm{OH}$ at the surface of $\mathrm{MCC}$. In addition, the long chain of the compatibilizer can result in physical entanglement with the PLA matrix [44]. Therefore, the stress transfer was more effective between the reinforcement and matrix and increased the mechanical properties of the MCC/PLA composites.

The mechanical properties of the MCC/PLA composites were gradually enhanced with increasing $D_{\mathrm{g}}$ of PLA-g-AMS/MAH, with optimal results for the PA4 sample. The tensile strength, flexural strength, impact strength, and elongation at break of the PCA4 sample were increased by $44,15.5,37.5$, and $38 \%$, respectively. This is due to the improved $D_{\mathrm{g}}$ of the PLA-g-AMS/MAH. With the use of AMS as a comonomer, more MAH monomers were grafted onto the PLA chain, facilitating the esterification reaction between PLA-g-AMS/MAH and MCC. Thus the composite had a better interfacial bonding effect, which resulted in higher mechanical properties.

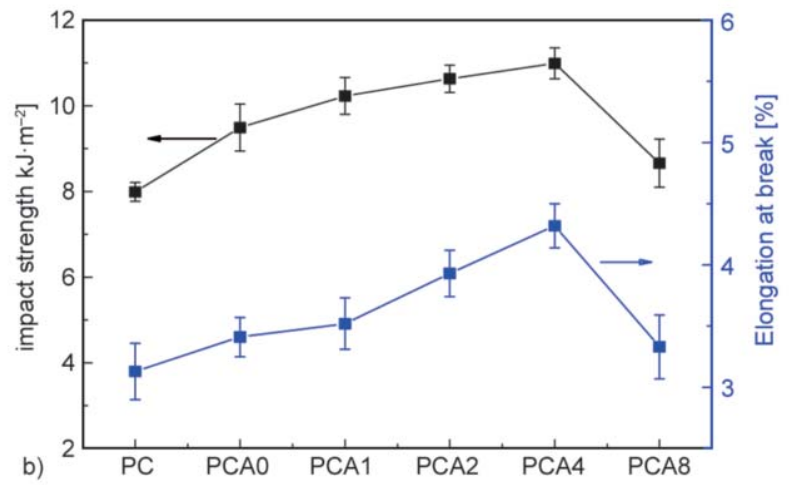

Figure 6. Mechanical properties of MCC/PLA composites prepared with different PLA-g-AMS/MAH: (a) tensile strength and flexural strength; (b) impact strength and elongation at break. 


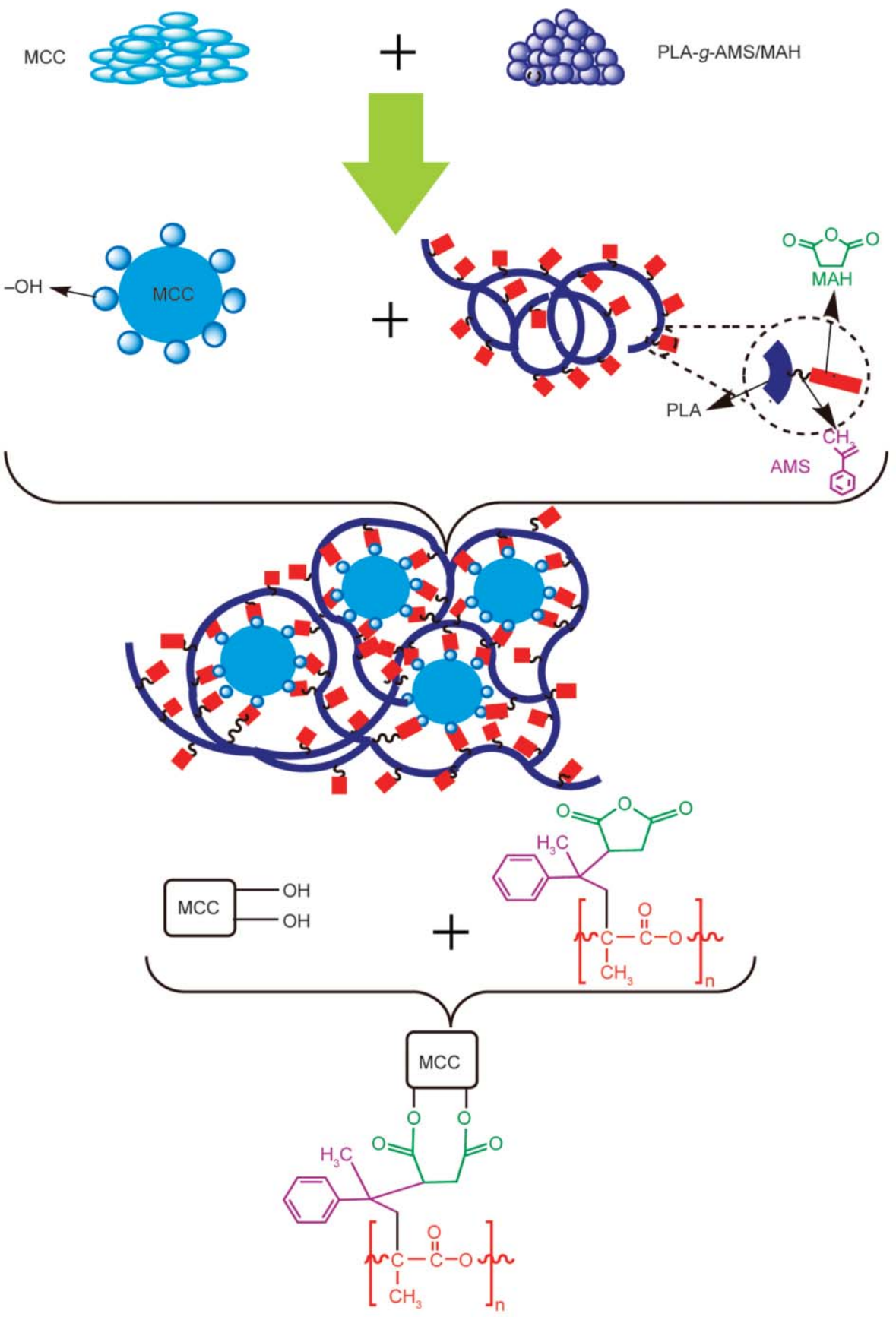

Figure 7. Possible reaction mechanism of MCC/PLA composites with PLA-g-AMS/MAH.

\subsection{SEM analysis}

Microscopic morphological analysis was performed to assess the compatibility of the composite materials. The SEM imaging of MCC/PLA composites is presented in Figure 8. There was an uneven distribution of MCC in the PLA matrix in the absence of PLA-g-AMS/MAH (Figure 8a). There were many holes due to the pulling out of MCC from the matrix, and a gap was clearly observed between the MCC and the PLA matrix. These phenomena verified that there was only a weak interaction between polar MCC and non-polar PLA.
As shown in Figure 8b-8f, the MCC were coated by the PLA matrix and the interface between the MCC and PLA became less clearly defined and lacking visible separation, suggesting improved interface adhesion between the filler and the matrix. With the addition of the PA4 compatibilizer, which exhibited the highest $D_{\mathrm{g}}$, the MCC was more uniformly dispersed and completely coated by the PLA matrix, resulting in the best interface compatibility. These results were related to the different $D_{\mathrm{g}}$ of PLA-g-AMS/MAH. As proposed in Figure 7, the anhydride groups on one end of the compatibilizer chains reacted with the 

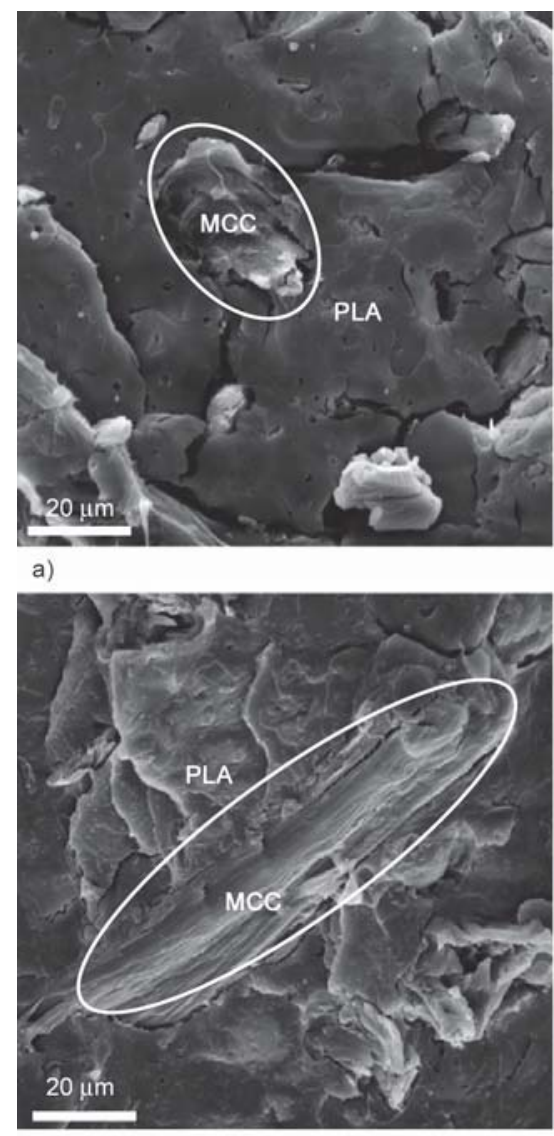

d)

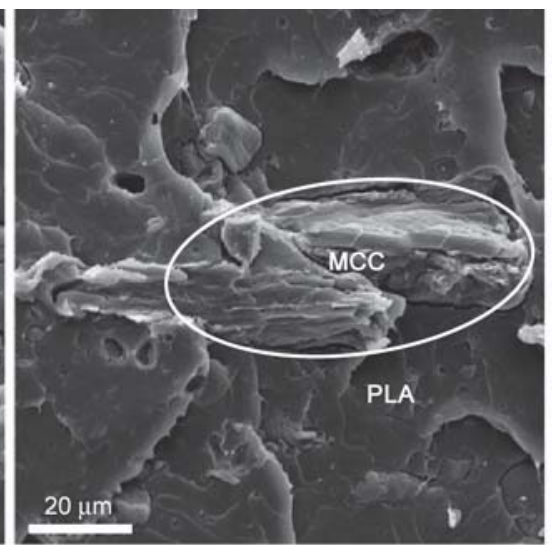

b)

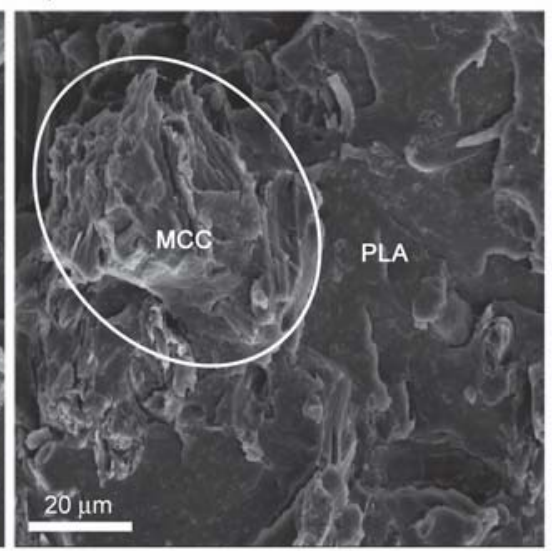

e)

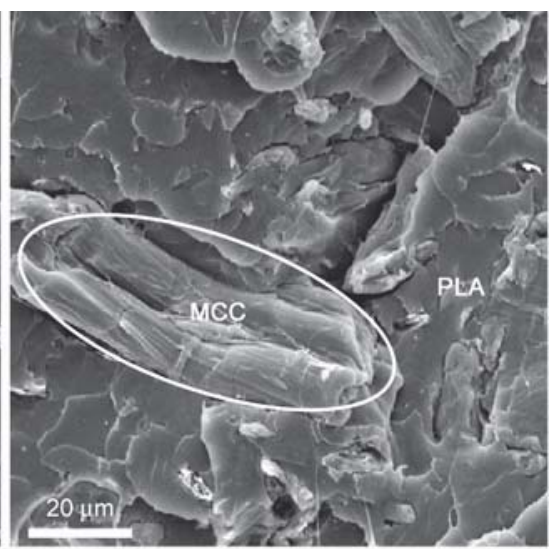

c)

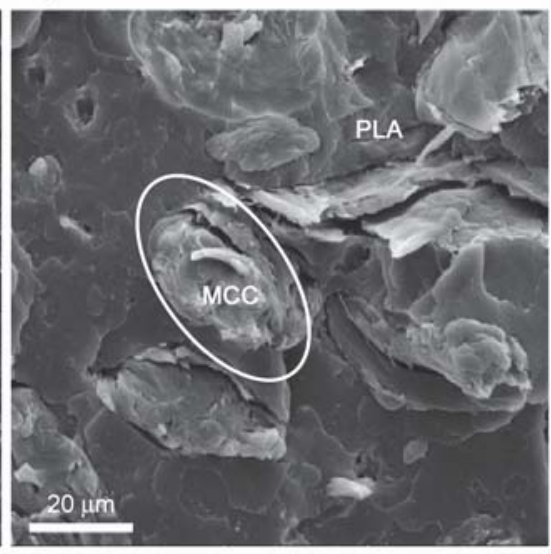

f)

Figure 8. SEM micrographs of the fractured surface of MCC/PLA composites prepared with different compatibilizers: (a) PC; (b) PCA0; (c) PCA1; (d) PCA2; (e) PCA4; (f) PCA8.

hydroxyl groups on the surface of MCC by esterification, as one component of the compatibilizing mechanism. The higher the $D_{\mathrm{g}}$ of the compatibilizer, the higher the number of acid anhydride groups available to react with the hydroxyl groups. Hence, the $D_{\mathrm{g}}$ of PLA-g-AMS/MAH effectively influences the properties of materials, so within a specific range, the interfacial compatibility of MCC/PLA composite increased with increased $D_{\mathrm{g}}$ of PLA- $g$ AMS/MAH. This explains the above measured rheological and mechanical properties.

\section{Conclusions}

In this study, PLA-g-AMS/MAH, a compatibilizer of MCC/PLA composites, was successfully prepared by free-radical melt grafted copolymerization using AMS as a comonomer. The $D_{\mathrm{g}}$ of MAH in the copolymer was correlated with the weight ratio of AMS/ $\mathrm{MAH}$, and the highest $D_{\mathrm{g}}$ value of $1.56 \mathrm{wt} \%$ was obtained for a ratio of 2:1 in the PA4 copolymer. PA4 exhibited the lowest MFR, indicating a higher molecular weight of PA4. The addition of copolymer compatibilizer affected the rheological and mechanical properties of the MCC/PLA composites. The storage modulus, complex viscosity, equilibrium torque, and shear heat of the MCC/PLA composites increased with increasing $D_{\mathrm{g}}$ of PLA-g-AMS/MAH and reached maximum values due to the presence of the highest $D_{\mathrm{g}}$ in the PA4 sample. Compared to the PC sample prepared without compatibilizer, the introduction of PA4 to the PCA4 sample resulted in increases in the tensile strength, flexural strength, impact strength, and elongation at breaks of $44,15.5$, 37.5 , and $38 \%$, respectively. Overall, our results showed that there was a positive correlation between the $D_{\mathrm{g}}$ of the compatibilizer and the compatibilization effect, which affected interfacial compatibility and further improved the properties of the $\mathrm{MCC} /$ PLA composites.

\section{Acknowledgements}

This work was financially supported by the Fundamental Research Funds for the Central Universities (no. 2572017PZ01) and the National Natural Science Foundation of China (no. 31100425). Further, this work was supported by Innovation and Entrepreneurship Leading Talent Program of Dongguan. 


\section{References}

[1] Rydz J., Sikorska W., Kyulavska M., Christova D.: Polyester-based (bio)degradable polymers as environmentally friendly materials for sustainable development. International journal of Molecular Sciences, 16, 564-596 (2015).

https://doi.org/10.3390/ijms16010564

[2] Khoshkava V., Kamal M. R.: Effect of cellulose nanocrystals (CNC) particle morphology on dispersion and rheological and mechanical properties of polypropylene/CNC nanocomposites. ACS Applied Materials and Interfaces, 6, 8146-8157 (2014). https://doi.org/10.1021/am500577e

[3] Chow W. S., Teoh E. L., Karger-Kocsis J.: Flame retarded poly(lactic acid): A review. Express Polymer Letters, 12, 396-417 (2018).

https://doi.org/10.3144/expresspolymlett.2018.34

[4] Zhou X., Yu Y., Lin Q., Chen L.: Effects of maleic anhydride-grafted polypropylene (MAPP) on the physico-mechanical properties and rheological behavior of bamboo powder-polypropylene foamed composites. Bioresources, 8, 6263-6279 (2013).

https://doi.org/10.15376/biores.8.4.6263-6279

[5] Yu H-Y., Qin Z-Y.: Surface grafting of cellulose nanocrystals with poly(3-hydroxybutyrate-co-3-hydroxyvalerate). Carbohydrate Polymers, 101, 471-478 (2014). https://doi.org/10.1016/j.carbpol.2013.09.048

[6] Petchwattana N., Covavisaruch S.: Mechanical and morphological properties of wood plastic biocomposites prepared from toughened poly(lactic acid) and rubber wood sawdust (Hevea brasiliensis). Journal of Bionic Engineering, 11, 630-637 (2014). https://doi.org/10.1016/s1672-6529(14)60074-3

[7] Farah S., Anderson D. G., Langer R.: Physical and mechanical properties of PLA, and their functions in widespread applications - A comprehensive review. Advanced Drug Delivery Reviews, 107, 367-392 (2016). https://doi.org/10.1016/j.addr.2016.06.012

[8] Shah A. A., Hasan F., Hameed A., Ahmed S.: Biological degradation of plastics: A comprehensive review. Biotechnology Advances, 26, 246-265 (2008). https://doi.org/10.1016/j.biotechadv.2007.12.005

[9] Auras R., Harte B., Selke S.: An overview of polylactides as packaging materials. Macromolecular Bioscience, 4, 835-864 (2004). https://doi.org/10.1002/mabi.200400043

[10] Blaker J. J., Nazhat S. N., Maquet V., Boccaccini A. R.: Long-term in vitro degradation of PDLLA/Bioglass ${ }^{\circledR}$ bone scaffolds in acellular simulated body fluid. Acta Biomaterialia, 7, 829-840 (2011). https://doi.org/10.1016/j.actbio.2010.09.013

[11] Pandey A., Aswath P.: Indentation creep reservoirs for drug-eluting poly(L-lactic acid) scaffolds. Journal of Biomaterials Science, 22, 1591-1606 (2011).

https://doi.org/10.1163/092050610x517103
[12] Zafar M. T., Zarrinbakhsh N., Mohanty A. K., Misra M., Maiti S. N., Ghosh A. K.: Biocomposites based on poly (lactic acid)/willow-fiber and their injection moulded microcellular foams. Express Polymer Letters, 10, 176186 (2016).

https://doi.org/info:doi/10.3144/expresspolymlett.2016.16

[13] Goh K., Heising J. K., Yuan Y., Karahan H. E., Wei L., Zhai S., Koh J-X., Htin N. M., Zhang F., Wang R., Fane A. G., Dekker M., Dehghani F., Chen Y.: Sandwich-architectured poly(lactic acid)-graphene composite food packaging films. ACS Applied Materials and Interfaces, 8, 9994-10004 (2016).

https://doi.org/10.1021/acsami.6b02498

[14] Graupner N., Herrmann A. S., Müssig J.: Natural and man-made cellulose fibre-reinforced poly(lactic acid) (PLA) composites: An overview about mechanical characteristics and application areas. Composites Part A: Applied Science and Manufacturing, 40, 810-821 (2009).

https://doi.org/10.1016/j.compositesa.2009.04.003

[15] Mathew A. P., Oksman K., Sain M.: Mechanical properties of biodegradable composites from poly lactic acid (PLA) and microcrystalline cellulose (MCC). Journal of Applied Polymer Science, 97, 2014-2025 (2005). https://doi.org/10.1002/app.21779

[16] Haafiz M. K. M., Hassan A., Zakaria Z., Inuwa I. M., Islam M. S., Jawaid M.: Properties of polylactic acid composites reinforced with oil palm biomass microcrystalline cellulose. Carbohydrate Polymers, 98, 139145 (2013).

https://doi.org/10.1016/j.carbpol.2013.05.069

[17] Wu D., Hakkarainen M.: Recycling PLA to multifunctional oligomeric compatibilizers for PLA/starch composites. European Polymer Journal, 64, 126-137 (2015). https://doi.org/10.1016/j.eurpolymj.2015.01.004

[18] Yang S., Madbouly S. A., Schrader J. A., Srinivasan G., Grewell D., McCabe K. G., Kessler M. R., Graves W. R.: Characterization and biodegradation behavior of bio-based poly(lactic acid) and soy protein blends for sustainable horticultural applications. Green Chemistry, 17, 380-393 (2015). https://doi.org/10.1039/c4gc01482k

[19] Yu H-Y., Zhang H., Abdalkarim S. Y. H., Yang L., Zhu J., Gu J., Yao J.: Interfacial compatible poly(ethylene glycol) chains modified cellulose nanosphere as bifunctional reinforcements in green polylatic acid for food packagings. Journal of the Taiwan Institute of Chemical Engineers, 95, 583-593 (2019).

https://doi.org/10.1016/j.jtice.2018.09.016

[20] Suryanegara L., Nakagaito A. N., Yano H.: The effect of crystallization of PLA on the thermal and mechanical properties of microfibrillated cellulose-reinforced PLA composites. Composites Science and Technology, 69, 1187-1192 (2009).

https://doi.org/10.1016/j.compscitech.2009.02.022 
[21] Li H., Cao Z., Wu D., Tao G., Zhong W., Zhu H., Qiu P., Liu C.: Crystallisation, mechanical properties and rheological behaviour of PLA composites reinforced by surface modified microcrystalline cellulose. Plastics Rubber and Composites, 45, 181-187 (2016). https://doi.org/10.1179/1743289815Y.0000000040

[22] Zheng Y., Fu Z., Li D., Wu M.: Effects of ball milling processes on the microstructure and rheological properties of microcrystalline cellulose as a sustainable polymer additive. Materials, 11, 1057/1-1057/13 (2018). https://oi.org/10.3390/ma11071057

[23] Murphy C. A., Collins M. N.: Microcrystalline cellulose reinforced polylactic acid biocomposite filaments for 3D printing. Polymer Composites, 39, 1311-1320 (2018). https://doi.org/10.1002/pc.24069

[24] Suchaiya V., Aht-Ong D.: Effect of microcrystalline cellulose from banana stem fiber on mechanical properties and crystallinity of PLA composite films. Materials Science Forum, 695, 170-173 (2011). https://doi.org/10.4028/www.scientific.net/MSF.695.170

[25] Orue A., Jauregi A., Unsuain U., Labidi J., Eceiza A., Arbelaiz A.: The effect of alkaline and silane treatments on mechanical properties and breakage of sisal fibers and poly(lactic acid)/sisal fiber composites. Composites Part A: Applied Science and Manufacturing, 84, 186195 (2016).

https://doi.org/10.1016/j.compositesa.2016.01.021

[26] Jandas P. J., Mohanty S., Nayak S. K., Srivastava H.: Effect of surface treatments of banana fiber on mechanical, thermal, and biodegradability properties of PLA/ banana fiber biocomposites. Polymer Composites, 32, 1689-1700 (2011).

https://doi.org/10.1002/pc.21165

[27] Zhang H.: Effect of a novel coupling agent, alkyl ketene dimer, on the mechanical properties of wood-plastic composites. Materials and Design, 59, 130-134 (2014). https://doi.org/10.1016/j.matdes.2014.02.048

[28] Tingaut P., Zimmermann T., Lopez-Suevos F.: Synthesis and characterization of bionanocomposites with tunable properties from poly(lactic acid) and acetylated microfibrillated cellulose. Biomacromolecules, 11, 454 464 (2010)

https://doi.org/10.1021/bm901186u

[29] Gregorova A., Hrabalova M., Wimmer R., Saake B., Altaner C.: Poly(lactide acid) composites reinforced with fibers obtained from different tissue types of Picea sitchensis. Journal of Applied Polymer Science, 114, 2616-2623 (2009).

https://doi.org/10.1002/app.30819

[30] Yu H-Y., Wang C., Abdalkarim S. Y. H.: Cellulose nanocrystals/polyethylene glycol as bifunctional reinforcing/compatibilizing agents in poly(lactic acid) nanofibers for controlling long-term in vitro drug release. Cellulose, 24, 4461-4477 (2017). https://doi.org/10.1007/s10570-017-1431-6
[31] Hwang S. W., Shim J. K., Selke S., Soto-Valdez H., Rubino M., Auras R.: Effect of maleic-anhydride grafting on the physical and mechanical properties of poly(Llactic acid)/starch blends. Macromolecular Materials and Engineering, 298, 624-633 (2013).

https://doi.org/10.1002/mame.201200111

[32] Detyothin S., Selke S. E. M., Narayan R., Rubino M., Auras R. A.: Effects of molecular weight and grafted maleic anhydride of functionalized polylactic acid used in reactive compatibilized binary and ternary blends of polylactic acid and thermoplastic cassava starch. Journal of Applied Polymer Science, 132, 1-15 (2015).

https://doi.org/10.1002/app.42230

[33] Chow W. S., Tham W. L., Seow P. C.: Effects of maleated-pla compatibilizer on the properties of poly(lactic acid)/halloysite clay composites. Journal of Thermoplastic Composite Materials, 26, 1349-1363 (2013). https://doi.org/10.1177/0892705712439569

[34] Gao H., Xie Y., Ou R., Wang Q.: Grafting effects of polypropylene/polyethylene blends with maleic anhydride on the properties of the resulting wood-plastic composites. Composites Part A: Applied Science and Manufacturing, 43, 150-157 (2012).

https://doi.org/10.1016/j.compositesa.2011.10.001

[35] Detyothin S., Selke S. E. M., Narayan R., Rubino M., Auras R.: Reactive functionalization of poly(lactic acid), PLA: Effects of the reactive modifier, initiator and processing conditions on the final grafted maleic anhydride content and molecular weight of PLA. Polymer Degradation and Stability, 98, 2697-2708 (2013). https://doi.org/10.1016/j.polymdegradstab.2013.10.001

[36] Li Y., Xie X-M., Guo B-H.: Study on styrene-assisted melt free-radical grafting of maleic anhydride onto polypropylene. Polymer, 42, 3419-3425 (2001). https://doi.org/10.1016/S0032-3861(00)00767-9

[37] Luo W., Liu X., Fu Y.: Melt grafting of maleic anhydride onto polypropylene with assistance of $\alpha$-methylstyrene. Polymer Engineering and Science, 52, 814819 (2012).

https://doi.org/10.1002/pen.22147

[38] Wu C-S.: Renewable resource-based composites of recycled natural fibers and maleated polylactide bioplastic: Characterization and biodegradability. Polymer Degradation and Stability, 94, 1076-1084 (2009). https://doi.org/10.1016/j.polymdegradstab.2009.04.002

[39] Yu T., Jiang N., Li Y.: Study on short ramie fiber/poly (lactic acid) composites compatibilized by maleic anhydride. Composites Part A: Applied Science and Manufacturing, 64, 139-146 (2014). https://doi.org/10.1016/j.compositesa.2014.05.008

[40] Ma P., Cai X., Lou X., Dong W., Chen M., Lemstra P. J.: Styrene-assisted melt free-radical grafting of maleic anhydride onto poly( $\beta$-hydroxybutyrate). Polymer Degradation and Stability, 100, 93-100 (2014). https://doi.org/10.1016/j.polymdegradstab.2013.12.005 
[41] Hwang S. W., Lee S. B., Lee C. K., Lee J. Y., Shim J. K., Selke S. E. M., Soto-Valdez H., Matuana L., Rubino M., Auras R.: Grafting of maleic anhydride on poly(L-lactic acid). Effects on physical and mechanical properties. Polymer Testing, 31, 333-344 (2012).

https://doi.org/10.1016/j.polymertesting.2011.12.005

[42] Du J., Wang Y., Xie X., Xu M., Song Y.: Styrene-assisted maleic anhydride grafted poly(lactic acid) as an effective compatibilizer for wood flour/poly(lactic acid) bio-composites. Polymers, 9, 623/1-623/12 (2017). https://doi.org/10.3390/polym9110623
[43] Yang W., Liu Z-Y., Shan G-F., Li Z-M., Xie B-H., Yang M-B.: Study on the melt flow behavior of glass bead filled polypropylene. Polymer Testing, 24, 490-497 (2005). https://doi.org/10.1016/j.polymertesting.2004.12.005

[44] Mohanty S., Nayak S. K.: Interfacial, dynamic mechanical, and thermal fiber reinforced behavior of MAPE treated sisal fiber reinforced HDPE composites. Journal of Applied Polymer Science, 102, 3306-3315 (2006). https://doi.org/10.1002/app.24799 